Conclusion Novel solutions that aim to reduce empiric therapy, or shorten the interval to treatment success, are critical. Through the use of sequential testing algorithms, more accurate discrimination between GU etiologies may help address the re-emergence of Syphilis in the USA.

Disclosure No significant relationships.

\section{P034 HIV SELF-TESTING AND POTENTIAL LINKAGE TO CARE AMONG MEN WHO HAVE SEX WITH MEN IN CHINA: A CROSS-SECTIONAL ONLINE SURVEY}

${ }^{1}$ Fan Yang, ${ }^{2}$ Weiming Tang, ${ }^{3}$ Cheng Wang*. ${ }^{1}$ University of North Carolina at Chapel Hill, Project-china, Guangzhou, China; ${ }^{2}$ UNC Project-China, Guangzhou, China; ${ }^{3}$ Dermatology Hospital of Southern Medical University, STD Control Department, Guangzhou, China

\subsection{6/sextrans-2019-sti.242}

Background HIV self-testing (HIVST) was recommended by the World Health Organization as an additional way for improving HIV testing due to its advantage in privacy and convenience. Studies showed that HIVST was well accepted among men who have sex with men(MSM) in China. This study aims to investigate the situation of HIVST usage, its correlates and implications for linkage to care among Chinese MSM.

Methods Data were collected from a nationwide online survey. Men who ever had sex with another man, were 16 years or older, born as a male, and ever tested for HIV were eligible. Survey collected information on HIVST and source of self-test kits. Sociodemographic and behavioral data were also collected and assessed in relation to HIVST through bivariate analyses. We characterized linkage to care after receiving a HIV-positive confirmatory results among self-testers and facility-based testers(i.e. who never self-tested).

Results Among 540 men who ever tested for HIV (age: 27.3 $\pm 6.6)$, most were never married $(87.4 \%, 472 / 540)$ and completed college $(52.2 \%, 282 / 540)$. 75.2\%(406/540) reported having been self-tested. Self-test kits were commonly obtained from community-based organizations $(54.4 \%, 221 / 406)$ and online $(46.6 \%, 189 / 406)$. HIVST was associated with college or higher education $(\mathrm{OR}=1.41,95 \% \mathrm{CI}$ : 1.03-1.96), but not with other socio-demographics, sexuality disclosure or condom use. 32/540 (5.9\%) men received confirmed HIV-positive results, $25 / 406(6.2 \%)$ among self-testers and $7 / 134$ $(5.2 \%$,$) among facility-based testers (\mathrm{p}=0.69)$. After receiving HIV-positive confirmatory results, all 25 self-testers sought care while $3 / 7(42.9 \%)$ facility-based testers did $(\mathrm{p}<0.001)$. Delays before seeking care were not significantly different between self-testers and facility-based testers $(P=0.366)$. 254/ $508(46.5 \%)$ men reported likely to test for HIV in next three months, similarly among self-testers and facility-based testers.

Conclusion Many men received HIVST. Men with higher education were more likely to be ever self-tested. The use of HIVST did not appear to hinder linkage to HIV care and services among men with confirmed HIV-positive results.

Disclosure No significant relationships.
P035 IMPACT OF MASS MEDIA EXPOSURE IN GETTING HIV TESTING AMONG URBAN WOMEN IN NEPAL

'Bikesh Bajracharya*, ${ }^{2}$ Milima Dangol. 'Support to the Health Sector Programme, Kathmandu, Nepal; ${ }^{2}$ Restless Nepal, Health, Patan, Nepal

10.1136/sextrans-2019-sti.243

Background According to Nepal Demographic and Health Survey (NDHS) 2016, 81\% of women have heard of AIDS in Nepal. Despite this, only $10 \%$ of women have ever been tested and received the results. The objective of the study is to examine the impact of mass media exposure in getting HIV testing among urban women in Nepal.

Methods The study is based on 12,862 women aged 15-49 residing in Nepal and enrolled in NDHS 2016. All urban women were asked the frequency of exposure to media. Binary logistic regression analysis was used to study the effect of radio, television and internet exposure in getting HIV testing among women in Nepal.

Results Among women exposed to radio, television and internet have $12.6 \%, 12.6 \%$ and $18.6 \%$ HIV testing respectively than those without radio (9.9\%), television $(8.1 \%)$ and internet $(8.3 \%)$. (P value $<0.001)$. Women exposed to radio, television and internet at least once a week were more likely to have HIV testing then those not exposed. Women who used the internet every day had high HIV testing (19.4\%, CI 18.9 to 19.8$)$ in comparison to those listened radio every day (13.6\%, CI 13.1 to 14.0$)$ and watch television every day (14.1\%, CI 13.7 to 14.5$)$. Using binary logistic regression analysis, odds of women exposed to radio, television and internet were $1.2,1.5$ and 2.5 times respectively more likely to have HIV testing than those not exposed ( $\mathrm{P}$ value $<0.001)$.

Conclusion Urban women exposure to internet has high impact in getting HIV test in Nepal. Internet plays a crucial role as a source of information for urban women in getting HIV testing in comparison to radio and television. The Ministry of Health, and International Development Partners should develop the intervention such as mobile apps, website as information source as more women are using mobile phone and internet in Nepal.

Disclosure No significant relationships.

\section{P036 PREDICTORS OF LOST TO FOLLOW-UP IN A 'TEST AND TREAT' PROGRAMME AMONG WOMEN WITH HIGH-RISK SEXUAL BEHAVIOUR IN KAMPALA, UGANDA}

${ }^{1}$ Onesmus Kamacooko*, ${ }^{2}$ Yunia Mayanja, ${ }^{2}$ Daniel Bagiire, ${ }^{3}$ Gertrude Namale, ${ }^{4}$ Janet Seeley. ${ }^{1}$ Medical Research Council/UVRI and London School of Hygiene and Tropical Medicine Uganda Research Unit, Statistics and Modelling, Kampala, Uganda; ${ }^{2}$ Medical Research Council/UVRI and London School of Hygiene and Tropical Medicine Uganda Research Unit, Kampala, Uganda; ${ }^{3}$ MRC/UVRI and LSHTM, HIV Intervention, Kampala, Uganda; ${ }^{4}$ London School of Hygiene and Tropical Medicine, London, UK

\subsection{6/sextrans-2019-sti.244}

Background Immediate uptake of antiretroviral therapy (ART) after an HIV-positive diagnosis (Test and Treat) is now being implemented in Uganda. Data are limited on lost to follow-up (LTFU) in high-risk cohorts that have initiated 'Test and Treat'. We describe LTFU in a cohort of women of high-risk sexual behaviour who initiated ART under 'Test and Treat'.

Methods We performed a retrospective cohort study of participant records at the Good Health for Women Project (GHWP) 